\title{
As Marcas do Real: interfaces entre ficção, memória e história em Resumo de Ana, de Modesto Carone
}

Rita de Cássia Silva Dionísio

Resumo

\begin{abstract}
Resumo de Ana, do crítico literário e ficcionista contemporâneo Modesto Carone, é uma narrativa dividida em duas partes distintas, dois contos complementares que contam, numa diç̧ão que mistura o exercício de lembranças com o constrangimento, as histórias de Ana e Ciro. São dois resumos, pois expõem, abreviadamente, a sucessão de acontecimentos de duas histórias de vida, extraindo delas as partes necessárias para compor a visão de conjunto e dar a impressão de totalidade. Esta pesquisa tenta verificar as condições de produção desse texto literário caroneano e suas articulações entre ficção, memória e história, considerando o contexto histórico da época em que o enredo dessa obra se desenvolve. Discutindo algumas questões sobre o contexto contemporâneo e pós-moderno, este trabalho fundamenta-se na afirmação de que, nessa obra caroneana, o condicionamento social e histórico da literatura não constitui apenas uma moldura, mas a própria substância da realidade artística.
\end{abstract}

Palavras-chave: Literatura. Ficção. Memória. História. Contemporâneo. Pósmoderno.

Romance e história são resultados da atividade do espírito humano que respondem, sempre, cada um em suas circunstâncias e segundo os códigos que lhe são próprios, às necessidades do tempo presente. O objeto da história é o passado. É a história que faz vir ao presente o que já não está mais aí. O objeto do romance é a imaginação do homem. É ele que traz ao nosso presente o que jamais esteve aí.

José Américo Miranda (In: BOECHAT, 2000, p. 17.)

Modesto Carone - crítico literário e ficcionista - nasceu em Sorocaba, São Paulo (1937). Foi jornalista e mais tarde professor de Literatura nas universidades de Viena (Áustria), Campinas e São Paulo (onde reside atualmente). Publicou dois livros de crítica literária - Metáfora e montagem (1974) e A poética do silêncio (1979) - e quatro de contos-As marcas do real (Prêmio Jabuti de 1980), Aos pés de Matilda (1980), Dias melhores (1984) e Nas garras de Praga (1993). É um escritor conhecido - pelo menos da crítica - e considerado um dos melhores contistas do Brasil, embora 
tenha, infelizmente, publicado muito pouco de sua produção particular, pois esteve, por vários anos, envolvido no fantástico projeto de traduzir diretamente do alemão para o português toda a obra de Franz Kafka (publicada pela Companhia das Letras).

Em Resumo de $A n a^{1}$, Modesto Carone constrói a narrativa dividida em duas partes distintas, dois contos complementares, mas que podem (e devem) ser lidos isoladamente. Um é resultado do outro, diálogo especular e espetacular, quase fotografias de uma mesma cena. De forma cronológica, vão sendo contadas, numa dicção que mistura o exercício de lembranças com o constrangimento, as histórias de Ana e Ciro. Contam a história dos mesmos personagens, sob diferentes olhares, pela voz do mesmo narrador - que raramente fala em primeira pessoa, porque seu interesse é recuperar a história dos parentes - que é também a sua própria história resgatá-la do passado e renová-la, com a compreensão do olhar retrospectivo.

A narrativa, que é surpreendentemente rica, ganha complexidade e se completa a partir da percepção subjetiva do leitor, graças ao jogo reflexivo da mudança do ângulo de observação. São dois resumos, pois expõem abreviadamente a sucessão de acontecimentos de duas histórias de vida, extraindo delas as partes necessárias para compor a visão de conjunto e dar a impressão de totalidade - totalidade apenas sugerida, porque ela própria não é possível de ser apreendida - evidenciando a existência de um vínculo direto do romance com os pressupostos da historiografia, pois o "contador de estória" silencia, exclui e elimina certos acontecimentos - e pessoas do passado para construir o seu relato².

Ana é mãe de Ciro. Ambos nasceram no interior de São Paulo: ela, em 1887, viveu encarcerada nos rituais domésticos e na luta pela sobrevivência, desfazendo-se numa vertigem arrastada e inexorável; ele, em 1925, personagem de um mundo precário, que trata o homem como peça de uma engrenagem, é o registro da própria decadência, conheceu as experiências marcadas por sofrimento e mal-estar. Os dois viveram penosamente, oprimidos pela necessidade e pela tendência a sonhar com comodidades e alegrias plausíveis, mas nunca ao alcance das mãos. É uma visão cruel, antilírica, cheia de violência degradante de pessoas que lutam para superar suas limitações. Nada há de notável em suas vidas. No entanto, de forma séria e respeitosa, o narrador faz com que a leitura assuma a grandeza e a compostura da observação dos destinos humanos. Vistas no fluxo do grande tempo histórico, aquelas duas vidas não só ficam abrigadas do esquecimento, como se impregnam da emoção durável das coisas inteligíveis.

Resumo de Ana é uma narrativa pós-moderna, contemporânea. Uma das principais características das narrativas desse momento literário é a interdisciplinaridade com a História, em que o processo de criação ficcional demonstra um diálogo intertextual com personagens e fatos, não havendo fronteiras na relação real/ficcional, configurando-se como um tipo de romance histórico. Sobre essa relação factual/ficcional, Carpeaux (1962, p. 3376), afirma que "uma das grandes seduções do romance histórico é a possibilidade de tecer comparações, mais ou menos subtendidas, mais meditadas ou mais baratas, com acontecimentos da história contemporânea".

O romance pós-moderno utiliza mundos históricos e reais para instaurar a representação ficcional e criar verdades imaginárias. Como afirma Hutcheon (1991, p. 142), "ele faz parte da postura pós-modernista de confrontar os paradoxos da representação fictícia/histórica, do particular/geral e do presente/passado". Na pósmodernidade, os textos não têm a pretensão de instaurar uma única verdade, em virtude da velocidade das informações e, por isso, da superação das "verdades" e do 
"novo", como afirma Arruda Filho (1999) em uma resenha crítica sobre Resumo de Ana:

[...] tudo é veloz. Fatos e eventos se sucedem entre a vertigem e a insensatez. O novo (ou aquilo que, travestido em rótulo e imagem, consideramos como "o" novo) parece ser apenas um pretexto para mudança constante. Não sobra muito tempo para quem quer fazer alguma reflexão sobre as diferenças que separam o transitório do permanente, o importante do supérfluo.

Resumo de Ana é um romance que apreende a realidade e tem a memória como elemento primordial de sua constituição, mesmo considerando que

ainda que se narrem os acontecimentos verídicos já passados, a memória relata não os próprios acontecimentos que já decorreram mas sim palavras concebidas pelas imagens daqueles fatos, os quais, ao passarem pelos sentidos, gravaram no espírito uma espécie de vestígio. (AGOSTINHO, 2001, p. 282.)

Os autores, na contemporaneidade, não têm o desejo de consagrar sua imagem autoral, optando também pela desmistificação do herói ${ }^{3}$. O romance contemporâneo apresenta características de outras épocas. Há, nele, uma explicitação do ato ficcional, com larga utilização da intertextualidade, evidenciando que só conhecemos o passado por meio de seus vestígios textualizados. ${ }^{4}$ Os dois contos que compõem Resumo de Ana travam um duelo muito interessante contra aquilo que se pode chamar "a liturgia do descartável", conforme apresenta Arruda Filho (1999):

Carone, com uma proposta audaciosa, talvez a mais importante de toda a sua produção literária, consegue transformar a banalidade da vida em literatura. Em outras palavras: ele quer mostrar, ao seu modo, o quanto é precária a memória, na medida em que seleciona alguns fragmentos da biografia de uma pessoa, ou de uma personagem, e os anula através do relato "oficial"-essa tragédia mentirosa, cheia de "grandiosidades épicas", em que transformamos as nossas vidas.

$\mathrm{Na}$ ótica ficcional de Carone, os pequenos desastres da vida, que em circunstâncias 'normais' estariam fadados ao esquecimento - por sua notória 'desimportância' - , aqui fazem parte de uma complexa história, não apenas de Ana e Ciro, mas - num universalismo inquietador, desconfortável - de muitas outras 'anas' e 'ciros', da "eterna dor de viver" dos seres humanos mortais e temporais, em diferentes lugares.

A primeira parte, "Resumo de Ana"5, subdivide-se em dez partes, sem títulos. O relato é intermediado por metatextos, nos quais o narrador evidencia a angústia - e, às vezes, fascínio - de Lazinha em relatar a história dos parentes:

Minha mãe hesitava à medida que o relato tomava corpo diante de mim: as pausas e as digressões se tornavam freqüentes e a disposição para recompor as falhas com novas reminiscências se acentuava. Embora difícil de definir, o gesto não era deliberado, parecendo refletir a forma de compromisso entre o fascínio de narrar e o medo de tratar as confidências de Ana como quem fere o decoro familiar. Mas ela venceu a dificuldade e passou à derrocada... (CARONE, 2001, p. 39)

"Ciro" se subdivide em catorze partes, também sem títulos. Nos dois contos, o corpo da escrita opera com a existência de várias vozes ${ }^{6}$ - ou "entidades"7: a voz de Ana, que confidencia sua história a Lazinha, sua filha mais velha; a voz de Lazinha, que é também personagem da história, que relata o passado ao seu filho; a voz de Anita, que se tornara companheira de Ciro até o fim da vida ${ }^{8}$; e a voz do próprio narrador, neto de Ana, filho de Lazinha (cujo nome não figura na narrativa) - que é, antes de tudo, o leitor de um texto narrado, que recolhe as memórias e palavras de 
sua mãe e de Anita e, revisitando os lugares outrora habitados pelos parentes certamente para conferir ao relato maior verossimilhança - dá-Ihes estrutura textual:

A lembrança é bruscamente interrompida pelo escapamento dos caminhões pesados que buscam saída para a Raposo Tavares, rumo ao Sul do país. Perto dali está o cruzamento com a Moreira César e a alguns passos a casa térrea de Lazinha. Embora o primeiro impulso seja dobrar à esquerda, [eu] caminho em linha reta até o último sinal vermelho [...] e para fugir à nuvem de fumaça entro numa padaria envidraçada. Dentro o barulho diminui e posso observar com calma o sobrado onde Ciro montou a gráfica falida. (CARONE, 2001, p. 92)

Talvez, para o nosso narrador,

Lembrar é [...] esquecer-se enquanto sujeito-objeto da lembrança, esgueirar-se para os cantos, colocar-se de certa forma à margem do texto - ser escrito por ele ao invés de escrevê-lo - para que a linguagem em processo intermitente de produção possa cumprir seu papel efetivo de socializador da memória. (MIRANDA, 1992, p. 120-121.)

Num discurso indireto livre, com linguagem enxuta, direta, rítmica - quase musical - e com economia de metáforas, os dois contos apresentam posturas narrativas similares e simultâneas: o narrador das memórias, que relata o que pertence à vida particular e familiar dos protagonistas, e o narrador historiador, que elenca fatos históricos reais para situar os personagens em um tempo determinado. A memória é operadora da diferença. Lembrar é descobrir, desconstruir, desterritorializar - atividade produtiva que tece com as idéias e imagens do presente a experiência do passado. ${ }^{9}$

Privilegiando a dimensão cronológica - com algumas digressões e desnivelamentos sobre o processo de recuperação da memória, presentificando as experiências - Modesto Carone compõe a narrativa em um período que vai do fim do século XIX à década de 90 do século XX, valendo-se da ironia, da intertextualidade e da iconografia como recursos textuais, tornando a ficção envolvente e interessante. $O$ autor intercala formas textualizadas diferentes (a referência ao jornal $O$ Estado de São Paulo, por exemplo) para instaurar o status ficção-verdade, de forma a pretender confundir sua própria linguagem com a realidade, o que também pode ser considerado marca do Pós-Modernismo. Em seu interessante estudo sobre o Pós-Modernismo, Hutcheon (1991, p. 173) diz que

Na metaficção historiográfica, não são apenas a literatura (séria ou popular) e a história que formam os discursos do pós-modernismo. Tudo - desde os quadrinhos e os contos de fadas até os almanaques e os jornais - fornece intertextos culturalmente importantes para a metafiç̧ão historiográfica.

Verifica-se, nesse ensaio, que as condições de produção do texto literário caroneano propõe articulações entre ficção, memória e história, levando-se em consideração o contexto histórico da época em que o enredo de suas narrativas se desenvolve. $O$ autor parece se valer de outras disciplinas, como a História, a Psicanálise, a Antropologia e a Sociologia para criar suas personagens e suas instigantes histórias, elaborando sua poética, enquanto prática discursiva que envolve outros campos de saberes, podendo-se considerar Resumo de Ana como uma metaficção historiográfica contemporânea. Resumo de Ana pode, ao nosso ver, ser considerado um resumo da história social brasileira - e, particularmente, paulistana e sorocabana - do século $\mathrm{XX}$, que explicita a realidade e as contradições do mundo capitalista, sob um olhar fora do poder, como diz BARTHES (1978, p. 16):

Mas a nós, que não somos nem cavaleiros da fé nem super-homens, só resta, por assim dizer, trapacear com a língua, trapacear a língua. Essa trapaça salutar, esse logro 
magnífico que permite ouvir a língua fora do poder, no esplendor de uma revolução permanente da linguagem, eu a chamo, quanto a mim: literatura.

A luta social permeia toda a narrativa, que se assenta na realidade, sem, no entanto, se desprender da estética romanesca. A literatura caroneana explicita a sua função social de ser, em essência, o resumo e o sumário de um tempo (WELLEK \& WARREN, [s.d.], p. 115). Nosso autor relata fatos da vida de pessoas que experimentam as dificuldades "vincadas de alto a baixo pela crueza da vida material" (CARONE, 2001, p. 103). Propor-se a analisar Resumo de Ana tem a ver com o questionamento do sentido da vida de "pessoas cujos rostos a escuridão oculta" (CARONE, 2001, p. 50), envolvendo-nos numa tarefa crítica da qual tão bem nos fala Lúcia Miguel Pereira (1998, p. 65):

De par com as misérias de que tanto nos queixamos, trouxe-nos o nosso tempo alguns bens, de que nunca falamos; e o maior é sem dúvida este de nos obrigar a refletir, a viver conscientemente; a reconhecer a estreita interdependência dos valores; a sentir a gravidade e a solidariedade das idéias; a ver que não existem divisões estanques entre a vida especulativa e a vida prática, que a coisa literária e a coisa pública se confundem no seu grande plano comum: a coisa humana.

Dessa forma, pensamos que o presente artigo fundamenta-se na afirmação de que o condicionamento social e histórico da literatura não constitui apenas uma moldura (sem que isso implique num atentado à sua autonomia), conforme Cândido (1987, p. 35), mas a própria substância da realidade artística e a condição de existência dos elementos que, nela, podem ser chamados de eternos, graças não a uma misteriosa participação em algo incondicionado, mas a uma forte virtude de eloqüência e generalidade.

\footnotetext{
Notas

1 Obra Resumo de Ana, publicada pela Companhia das Letras, em 2001 - 2a edição-(Prêmio Jabuti, categoria romance, em 1999).

2 FERNANDES (1996, p. 33) chama de processo metonímico essa forma de condensar, resumir para ganhar tempo, ser mais contundente e sugestivo, que é exatamente o que constatamos no processo narracional caroneano.

${ }^{3} \mathrm{O}$ romance histórico contemporâneo se diferencia, tematicamente, do romance histórico tradicional. Já não se descrevem os grandes feitos de uma nação e nem se constroem heróis, individuais ou coletivos, representativos de um povo. A construção da nação e a exaltação de um povo dão lugar a uma (re)visão crítica e desmistificadora do passado reconstruído pela ficção. (OLIVA, 1999, p. 124).

${ }^{4} \mathrm{~A}$ intertextualidade pós-moderna é uma manifestação formal de um desejo de reduzir a distância entre o passado e o presente do leitor e também de um desejo de reescrever o passado dentro de um novo contexto. Não é um desejo modernista de organizar o presente por meio do passado ou de fazer com que o presente pareça pobre em contraste com a riqueza do passado. (HUTCHEON, 1991, p. 157).

${ }^{5}$ A primeira versão de Resumo de Ana foi publicada na revista Novos Estudos CEBRAP, número 25, de outubro de 1989. Ciro é inédito. (CARONE, 2001, p. 114).

${ }^{6}$ A propósito da polifonia discursiva, é interessante observarmos que o problema que ela apresenta não é apenas de ponto de vista, ou seja, da maneira que se observa o que se conta. É também uma questão de consciência, ligada ao conhecimento que tem o narrador daquilo que narra, sua distância em relação aos personagens e a tudo o mais que envolve a história. O narrador pode estar próximo do que conta ou mesmo ser personagem do que conta, conforme Fernandes (1996, p. 12). Essa heteroglossia (BURKE, 1992, p. 15 e 336) descentraliza a antiga visão unilateral do discurso histórico.

7 Conforme Umberto Eco em sua análise da polifonia, no romance Sylvie, de Gerard de Nerval (ECO, 1994, p. 19, 20).

8 "...segundo Anita..."; "Anita só conseguiu falar dele muito mais tarde, numa conversa na varanda da casa de Lazinha." (CARONE, 2001, p. 96).

${ }^{9}$ Conforme Miranda (1992, p. 120), é preciso "desfiar o tecido dos acontecimentos e sentimentos pretéritos e transformá-lo numa urdidura sempre renovada, refeita, recriada, que não se encerra na busca do eu perdido por uma subjetividade onipotente, nem resulta na preservação do hábito e da rotina. Entendida como repetição em demanda da diferença, a atividade memorialista propicia tomar-se o passado como
} 
"lugar de reflexão", para que a memória, então problematizada, atue também como espécie de metamemória $[\ldots]$ ".

Abstract

Resumo de Ana, by fictionist and contemporary literary critic Modesto Carone, is a narrative divided into two distinct parts. The complementary tales of Ana and Ciro come together and intertwine constraint with the exercising of memories. The stories are summaries that work together by extracting the necessary succession of events from their lives to compose a complete view and give the impression of totality or oneness. This research paper will verify the conditions under which this Caroneian work was produced and its articulation between fiction, memory and history as it considers the historical context of the period in which the narrative's plot is developed. This research will debate and be based on theories about the contemporary and postmodern context of this Caroneian work and the affirmation that the social and historical conditioning of the literature does not constitute only a mold, but the selfsame substance of the artistic reality.

Key words: Literature. Fiction. Memory. History. Contemporary. Postmodern.

Referências

AGOSTINHO. Confissões. Tradução de J. Oliveira Santos e A. Ambrósio de Pina. Petrópolis: Vozes, 2001.

ARRUDA FILHO, Raul. Resumo de Ana - A luta entre a memória, a linguagem e a emoção. A Notícia. Joinville, 4 mar. 1999.

AUERBACH, Erich. Mímesis, a representação da realidade na literatura ocidental. São Paulo: Perspectiva, 1994.

BARTHES, Roland. Aula. São Paulo: Cultrix, 1978.

BARTHES, Roland. Sobre o conceito de História. In: Obras

Escolhidas-Magia e Técnica, arte e política. Tradução de Sérgio

Paulo Rouanet. São Paulo: Brasiliense, 1986. p. 222-232.

BENJAMIN, Walter. Obras Escolhidas - magia e técnica, arte e política. São Paulo: Brasiliense, 1986.

BOECHAT, Maria Cecília Bruzzi; OLIVEIRA, Paulo Mota; OLIVEIRA, Silvana Maria Pessoa de (Org.). Romance histórico: recorrências e transformações. Belo Horizonte: FALE/UFMG, 2000. 
BURKE, Peter. A escrita da História: novas perspectivas. São Paulo: UNESP, 1992

CARONE, Modesto. Resumo de Ana. 2. ed. São Paulo: Companhia das Letras, 2001.

CARPEAUX, Otto Maria. História da Literatura Ocidental. Rio de Janeiro: Edições O Cruzeiro, 1962. v. VII.

FOSTER, H.; HABERMAS, J. y otros. La posmodernidad.

Barcelona: Kayrós. 1985.

GAGNEBIN, Jeanne Marie. História e narração em Walter

Benjamim. São Paulo: Perspectiva, 1994.

GUIMARÃES, César. Imagens da memória: entre o legível e o visível. Belo Horizonte: Pós-Graduação em Letras: Estudos Literários — FALE/UFMG / Ed. UFMG, 1997.

HUTCHEON, Linda. Poética do Pós-Modernismo: história, teoria e ficção. Rio de Janeiro: Imago, 1991.

JAMESON, Fredric. Pós-Modernismo: a lógica cultural do capitalismo tardio. São Paulo: Ática, 1996.

LE GOFF, Jacques. História e memória. Trad. Bernardo Leitão et al. Campinas: Ed. UNICAMP, 1990.

LIMA, Luís Costa. A aguarrás do tempo. Rio de Janeiro: Rocco, 1989.

LIMA, Luís Costa. Sociedade e Discurso Ficcional. Rio de Janeiro: Guanabara, 1986.

LYOTARD, Jean-François. La Condition Postmoderne. Paris: Lês Éditions De Minuit, 1979.

MALLARD, Letícia. O Factual e o Ficcional: literatura e história. Suplemento Literário de Minas Gerais. Belo Horizonte, n.21, p. 2123, mai. 1997.

PEREIRA, Lúcia Miguel. Sobre a Crítica (O ofício de compreender, Crítica e Controvérsia, Vida, obra e leitura crítica). In: A leitora e seus personagens. Rio de Janeiro: Graphia, 1998. p. 65.

MIRANDA, Wander Melo (Org.). Narrativas da Modernidade. Belo Horizonte: Autêntica, 1999.

MIRANDA, Wander Melo. Corpos Escritos: Graciliano Ramos e Silviano Santiago. São Paulo: EDUSP; Belo Horizonte: Ed. UFMG, 1992.

OLIVA, Osmar Pereira. Agosto e o discurso marginal fonsequiano. Dissertação de Mestrado. Faculdade de Letras, Universidade Federal de Minas Gerais, Belo Horizonte, 1999.

PERRONE-MOISÉS, Leyla. Texto, Crítica e Escritura. São Paulo: Ática, 1978. 
PERRONE-MOISÉS, Leyla. Promessas, encantos e amavios. Flores na escrivaninha: Ensaios. São Paulo: Companhia das Letras, 1997a. p. 13-20.

TAVARES, Cássio da Silva Araújo. O conto e o conto brasileiro contemporâneo. São Paulo: FFLCH-LE (USP), 2003.

WELLEK, René; WARREN, Austin. Teoria da Literatura. Mira-Sintra - Mem Martins: Publicações Europa-América, s.d. 